\title{
Modified one-piece extended transbasal approach for translamina terminalis resection of retrochiasmatic third ventricular craniopharyngioma
}

\author{
JAMES K. LiU, M.D. \\ Departments of Neurological Surgery and Otolaryngology-Head and Neck Surgery, Center for Skull Base and \\ Pituitary Surgery, Neurological Institute of New Jersey, University of Medicine and Dentistry of New Jersey, New \\ Jersey Medical School, Newark, New Jersey
}

\begin{abstract}
Retrochiasmatic third ventricular craniopharyngiomas are formidable tumors to remove surgically. Access to the third ventricle can be achieved through the lamina terminalis corridor. A skull base approach to the lamina terminalis can be performed using either an anterolateral approach (orbitozygomatic, pterional, supraorbital) or a midline approach (extended transbasal, subfrontal). The major disadvantage of an anterolateral approach is the lack of visualization of the ipsilateral wall of the third ventricle and hypothalamus. However, a midline transbasal approach eliminates this blind spot thereby providing direct visualization of both ependymal walls for safe dissection of the tumor. In this operative video manuscript, the author demonstrates an illustrative step-by-step technique for translamina terminalis resection of a retrochiasmatic retroinfundibular craniopharyngioma within the third ventricle via a modified one-piece extended transbasal approach. This approach uses the standard bifrontal craniotomy and incorporates the anterior wall of the frontal sinus as a one-piece flap. The inferior limit of the osteotomy is based along the coronal contour of the anterior skull base which eliminates any bony overhang that can obstruct the line of sight to the lamina terminalis. Additional removal of the supraorbital bar is not necessary. The operative technique for this skull base approach and surgical nuances for craniopharyngioma resection are illustrated in this video atlas.

The video can be found here: http://youtu.be/E3Bsp6dUdAE.
\end{abstract}

(http://thejns.org/doi/abs/10.3171/2013.V1.FOCUS12354)

KEY WORDS $\bullet$ transbasal approach $\bullet$ translamina terminalis $\bullet$ resec-
tion $\bullet$ retrochiasmatic $\bullet$ craniopharyngioma $\bullet$ video

Manuscript submitted November 10, 2012.

Accepted November 26, 2012.

Please include this information when citing this paper: DOI: 10.3171/2013.V1.FOCUS12354.

Address correspondence to: James K. Liu, M.D., Department of Neurological Surgery, University of Medicine and Dentistry of New Jersey, New Jersey Medical School, 90 Bergen Street, Suite 8100, Newark, New Jersey 07101. email: james.liu@umdnj.edu. 